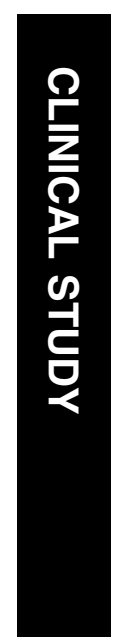

\section{Quality of fixation in eyes with neovascular age-related macular degeneration treated with ranibizumab}

Introduction

Pivotal phase III trials on treatment of neovascular age-related macular degeneration (NV-AMD) with monthly intravitreal injections of ranibizumab have shown stabilization or improvement in visual acuity. ${ }^{1,2}$ The recent study that compared pro re nata dosing strategies with monthly ranibizumab showed similar outcomes but the outcomes in real-life does not always mirror the clinical trial results. ${ }^{3,4}$ Although the treating ophthalmologists are satisfied by a five-lettergain in vision, most patients struggle to read well while the others are unable to cope with more complex activities in their daily life.

Visual acuity represents foveal function only, and changes in visual acuity do not always mirror anatomical response. ${ }^{5,6}$ Reading vision is determined by the location and stability of fixation. ${ }^{7}$ We had recently reported that the location of fixation is predominantly central and stable in ranibizumab-treated eyes compared with untreated eyes with disciform scars using microperimetry. ${ }^{8}$ González et $a l^{9}$ observed that fixation stability and visual acuity improved in ranibizumab-treated eyes compared with the healthy fellow eyes. These studies suggest that anatomical parameters of the macula may determine the fixation characteristics of the patients. Therefore, in this study, we evaluated quantitative factors on OCT that may potentially determine fixation characteristics in ranibizumab-treated eyes with NV-AMD.

\section{Materials and methods}

The study was performed in the Laser and Retinal Research Unit at King's College Hospital. All the measurements adhered to the 
tenets of the Helsinki agreement, the study was approved by the Chair of the Ethics Committee.

\section{Inclusion criteria}

Consecutive patients aged 55 years or older with at least 12-month follow-up for ranibizumab therapy for neovascular AMD were included in this study. The best-corrected visual acuity (BCVA) at baseline ranged between 24 and 73 ETDRS letters. All lesion subtypes were included, that is, classic, minimally classic, and occult choroidal neovascular membranes (CNVs). Exclusion criteria were CNVs due to causes other than AMD, prior photodynamic therapy or any other antiVEGF therapy, and vitrectomy or submacular surgery.

\section{Ranibizumab treatment regimen}

All included patients received three intravitreal injections with ranibizumab at monthly intervals. The decision to retreat after three injections was based on the following criteria: (1) recurrence of any subretinal fluid or intraretinal fluid on OCT in a previously dry macula; (2) persistent subretinal fluid or intraretinal fluid on OCT; (3) new-onset haemorrhages on fundus examination; (4) decrease of five letters or more associated with fluid on OCT or (5) new classic CNV. The numerical changes in central retinal thickness and the presence of PED were not taken into account to decide retreatment.

\section{Visual acuity measurement}

BCVA for each eye was measured using standard ETDRS protocol at $2 \mathrm{~m}$ distance with a modified ETDRS distance chart by a certified examiner on the day of the fixation test. Visual acuity was scored as the total number of ETDRS letters read correctly.

\section{Assessment of location and stability of fixation using MP-1 microperimetry}

The Nidek microperimeter (MP1, Nidek Instruments, Nidek, Padova, Italy) was used to measure fixation with a white fixation cross of height $3^{\circ}$ presented on a dark background on the LCD screen of the microperimeter. The fixation cross was presented at the maximum luminance of the microperimeter. Subjects were encouraged to use peripheral retina to look towards the centre of the cross if needed. Once subjects had located the cross, fixation was measured for a period of $30 \mathrm{~s}$. Eye position was recorded by tracking a retinal landmark at $25 \mathrm{~Hz}$ throughout the fixation assessment.
The pattern of fixation was classified based on location and stability using the MP-1 software as recommended by Fujii et al. ${ }^{10}$ In brief, the location of fixation is defined as the position of fixation with respect to the centre of the foveal avascular zone, and stability of fixation is defined as the ability of the eye to maintain a stable fixation in the preferred retinal locus.

The location of fixation was defined as predominantly central fixation when $>50 \%$ of the preferred fixation points were located within 2 degrees of the fovea; poor central fixation when $<50 \%$ but $>25 \%$ of the preferred fixation points were within 2 degrees of fovea, and predominantly eccentric fixation when $<25 \%$ of the preferred fixation points were located within the $2^{\circ}$-circle of the fovea.

The stability of fixation was based on the variation of the preferred retinal locus. The location of fixation was defined as stable fixation when $>75 \%$ of the fixation points were located within a predetermined limit area of variation of a $2^{\circ}$-diameter circle centred in the gravitational centre of all fixation points, regardless of the position of the foveal centre. The location of fixation was classified as relatively unstable fixation when $<75 \%$ of the fixation points were located within a $2^{\circ}$-diameter circle, but $>75 \%$ of the fixation points were located within a 4 -diameter circle. The location of fixation was classified as unstable fixation when $<75 \%$ of the fixation points were located within a $4^{\circ}$-circle.

\section{Calculation of bivariate contour ellipse area}

Crossland et al ${ }^{11}$ reported that quantifying fixation stability by calculating a bivariate contour ellipse area (BCEA) that encompasses $68 \%$ of fixations is a more powerful and accurate tool than the in-built fixation software of MP-1 for patients with macular diseases. The log BCEA is strongly correlated with reading speed in AMD. The BCEA $=2.28 \pi \sigma_{\mathrm{H}} \sigma_{\mathrm{V}}\left(1-\rho^{2}\right)^{1 / 2}$ where $\sigma_{\mathrm{H}}$ and $\sigma_{\mathrm{V}}$ are the standard deviations of fixation position in the horizontal and vertical meridian, respectively, and $\rho$ is the product-moment correlation of these two components. Therefore, this formula was used to calculate BCEA using Microsoft Excel 2010 (Seattle, WA, USA).

\section{Optical coherence tomography characteristics}

The average macular thickness (AMT), central subfield thickness (CST), and macular volume were obtained from the software of the Cirrus spectral domain (Carl Zeiss Meditec Inc., Dublin, CA, USA). The presence of intraretinal or subretinal fluid was also determined from the macular cube scans obtained on the same day that fixation was tested. 


\section{Statistical methods}

Baseline group characteristics were summarized using descriptive statistics. The analysis of variance was done to assess whether the location and stability of fixation was influenced by the age, visual acuity, AMT, CST, and macular volume. Fisher's exact test was done for categorical parameters such as the presence of macular fluid and angiographic lesion subtype. Logarithmic transformation of BCEA was done and correlated to $\log$ MAR conversion of the ETDRS letters. Multiple regressions of the variables were done to assess significant predictors of fixation.

\section{Results}

\section{Baseline characteristics}

The baseline features of the patients included in the study are shown in Table 1.

\section{Fixation pattern}

The location of fixation was predominantly central in $52.6 \%$, although a small proportion of the patients $(9.2 \%)$ had poor central fixation. The fixation in the remaining cohort $(38.2 \%)$ was predominantly eccentric. The fixation was stable in $65 \%$, relatively unstable in $25 \%$, and unstable in $10 \%$.

Table 1 Baseline characteristics

\begin{tabular}{lc}
\hline & $\begin{array}{c}\text { Neovascular AMD on ranibizumab } \\
\text { therapy }(\mathrm{n}=77)\end{array}$ \\
\hline Mean age (mean $\pm \mathrm{SD})$ & $79.5 \pm 12.2$ years \\
Males & $31.6 \%$ \\
BCVA (mean $\pm \mathrm{SD})$ & $48.5 \pm 16.5$ letters \\
AMT (mean \pm SD) & $275 \pm 83.8 \mu \mathrm{m}$ \\
Proportion of patients with SRF & $16(21 \%)$ \\
Proportion of patients with IRF & $28(37 \%)$ \\
Proportion of patients with & $10(13 \%)$ \\
both IRF and SRF & \\
\hline
\end{tabular}

Abbreviations: AMD, age-related macular degeneration; AMT, average macular thickness; BCVA, best-corrected visual acuity; IRF, intraretinal fluid; SD, standard deviation; SRF, subretinal fluid.
In patients with predominantly eccentric fixation $(n=29)$, the relation of the eccentric fixation relative to the centre of the lesion was superior in $38 \%$, inferior in $21 \%$, nasal in $24 \%$, and temporal in $17 \%$.

\section{Analysis of OCT characteristics}

The AMT, CST, and macular volume were not significantly different between the three types of fixation location and stability (Table 2). Neither the presence of any macular fluid nor angiographic lesion subtype was different between groups (Fisher's exact test $P=0.7$ and $P=0.62$, respectively).

\section{Visual acuity}

Visual acuity was significantly higher in the eyes with central and stable fixation compared with the other types of fixation. However, there was no cutoff points of visual acuity below which fixation was eccentric or unstable.

\section{Bivariate contour ellipse area}

The correlation matrix (Table 3) shows that the log BCEA correlated significantly only with $\log \mathrm{MAR}$ visual acuity. None of the OCT parameters (AMT, CST, and macular volume correlated with log BCEA. BCEA did not correlate to the total number of injections given $(P=0.66)$.

A multiple linear regression was performed to determine the determinants of fixation. The overall regression was significant, $F=4.27, P<0.002$. However, the $R^{2}$ was 0.241 and the adjusted $R^{2}$ was 0.185 , indicating that these variables as a group can predict only $24 \%$ of the variance in fixation in the sample. The adjusted $R^{2}$ of $18.4 \%$ is the estimated amount as extrapolated to the population. The reduction of the adjusted $R^{2}$ also indicates that the fixation cannot be predicted with these variables as a group.

In conclusion, visual acuity is the only variable in this group that can predict fixation.

\section{Discussion}

This study shows that most patients initiated on ranibizumab therapy have stable and centrally located

Table 2 Relation of OCT characteristics and the various types of fixation

\begin{tabular}{|c|c|c|c|c|c|c|c|c|}
\hline & $P C$ & POC & $P E$ & P-value & $S$ & RUS & US & P-value \\
\hline AMT $(\mu \mathrm{m} ;$ mean $\pm \mathrm{SD})$ & $247 \pm 56$ & $202 \pm 21$ & $250 \pm 43$ & 0.177 & $246 \pm 60.6$ & $245 \pm 111.5$ & $232 \pm 67.2$ & 0.76 \\
\hline $\mathrm{CST}(\mu \mathrm{m} ;$ mean $\pm \mathrm{SD})$ & $262 \pm 88$ & $226 \pm 96$ & $278 \pm 110$ & 0.41 & $260 \pm 81$ & $267 \pm 129$ & $276 \pm 121$ & 0.82 \\
\hline BCVA (ETDRS letters; mean \pm SD) & $56 \pm 14$ & $40 \pm 19$ & $40 \pm 13$ & 0.0001 & $53 \pm 15$ & $40 \pm 16$ & $43 \pm 15$ & 0.007 \\
\hline
\end{tabular}

Abbreviations: AMT, average macular thickness; BCVA, best-corrected visual acuity; CST, central subfield thickness; PC, predominantly central fixation; $\mathrm{PE}$, predominantly eccentric fixation; POC, poor central fixation; RUS, relatively unstable fixation; S, stable fixation; US, unstable fixation. $P$-value (ANOVA test). 
Table 3 Correlation matrix of the bivariate contour ellipse area with various variables

\begin{tabular}{|c|c|c|c|c|c|c|}
\hline & $\log M A R$ & $A M T$ & VOL & CST & Age & $\log B C E A$ \\
\hline \multirow[t]{2}{*}{ LogMAR } & & 0.034 & -0.197 & 0.076 & 0.178 & 0.457 \\
\hline & 1 & $P=0.77$ & $P=0.15$ & $P=0.522$ & $P=0.13$ & $P=0.00004$ \\
\hline \multirow[t]{2}{*}{ AMT } & 0.034 & & 0.623 & 0.659 & -0.295 & 0.052 \\
\hline & $P=0.77$ & 1 & $P=0.000$ & $P=0.000$ & $P=0.001$ & $P=0.66$ \\
\hline \multirow[t]{2}{*}{ VOL } & -0.197 & 0.623 & & 0.586 & -0.311 & -0.155 \\
\hline & $P=0.15$ & $P=0.000$ & 1 & $P=0.000$ & $P=0.007$ & $P=0.19$ \\
\hline \multirow[t]{2}{*}{ CST } & 0.076 & 0.659 & 0.586 & & -0.382 & 0.098 \\
\hline & $P=0.522$ & $P=0.000$ & $P=0.000$ & 1 & $P=0.0008$ & $P=0.41$ \\
\hline \multirow[t]{2}{*}{ Age } & 0.178 & -0.295 & -0.311 & -0.382 & & 0.141 \\
\hline & $P=0.13$ & $P=0.001$ & $P=0.007$ & $P=0.0008$ & 1 & $P-0.234$ \\
\hline \multirow[t]{2}{*}{ Log BCEA } & 0.457 & 0.052 & -0.155 & 0.098 & 0.141 & \\
\hline & $P=0.00004$ & $P=0.066$ & $P=0.19$ & $P=0.41$ & $P=0.234$ & 1 \\
\hline
\end{tabular}

Abbreviations: AMT, average macular thickness; BCEA, bivariate contour ellipse area; CST, central subfield thickness; VOL, macular volume.

fixation. Fixation was measured using two techniques: the in-built Nidek software and the BCEA. In both the methods, visual acuity is the only parameter that correlated significantly with the location of fixation.

Previous studies have shown that improvement in retinal sensitivity is a more reliable predictor of central and stable fixation compared with visual acuity. ${ }^{12,13}$

A recent report indicated that the most pronounced effect of intravitreal ranibizumab on visual acuity and retinal sensitivity was at 1 week after first injection, and that the effect was less pronounced with the second and third injections of the loading phase. ${ }^{14}$ On the contrary, Parravano et al ${ }^{15}$ noted that although maximum gain in visual acuity is at 4 weeks, retinal sensitivity continued to improve until the end of the study at 6 months. All patients in this study had at least 12 months of follow-up. Hence, this study shows that in the second year of therapy, visual acuity remained a determinant of fixation characteristics.

A model based on clinical trials on ranibizumab indicated that a total of 8.1 injections are required to maintain the initial gain of vision obtained during the induction period. ${ }^{16}$ This model was substantiated by a recent report that showed that increased frequency of injections is a predictor of better visual outcome, and is independent of the presence of macular fluid. ${ }^{17}$ Our study did not show any such relation between central fixation and number of injections.

The location of fixation was independent of the thickness or volume of the macula. In a cross-sectional study on diabetic macular oedema, the location of fixation was also not influenced by the morphological type of oedema. ${ }^{18}$ On the contrary, the location of fixation shifted to central after intravitreal triamcinolone in both diabetic macular oedema and central retinal vein occlusion, and the changes in the location of fixation correlated negatively to the retinal thickness. ${ }^{19,20}$ This may be because the location of fixation is dependent on the integrity of the photoreceptor layer. Future studies should aim to correlate the fixation characteristics with the integrity of the photoreceptor layer on OCT.

The location of fixation may also be dependent on other factors that were not determined in this study. For example, in central serous retinopathy, fixation was found to remain stable and central in some eyes despite a decrease in visual acuity and retinal sensitivity. ${ }^{21}$ Cone density alone was found to be an insufficient parameter to determine the location of fixation. ${ }^{22}$ Similarly, the impact of changes in binocular fixation characteristics due to improvement in vision in one eye in the eyes with bilateral NV-AMD was not accounted for in this study. ${ }^{23}$ Further studies on autofluorescence and morphological characteristics of the macula may also provide insight into the determinants of fixation. It is also useful to explore the parameters that influence the change in fixation during the course of the treatment for NV-AMD.

In summary, this study showed that visual acuity correlated significantly with the location and stability of fixation in eyes treated with ranibizumab for NV-AMD with at least 12 months of follow-up. We also observed that quantitative parameters of macula on OCT do not provide any correlation with position or stability of fixation, very much in keeping with studies that showed no correlation of visual acuity with central macular thickness. The observations highlight the need for early diagnosis and prompt treatment of patients with NV-AMD to ensure central and stable fixation.

Moreover, although central fixation correlated with BCVA overall, patient with poor visual acuity can still have central fixation. Hence, further studies should focus on morphological characteristics of the macula to better understand the features that determine central and stable fixation. Meanwhile, fixation test on microperimetry is easy and quick, and should be incorporated into visual 
rehabilitation clinics in order to suggest appropriate fixation training.

\section{Summary}

What was known before

- Significantly higher proportion of patients with wet age-related macular degeneration treated with intravitreal ranibizumab have central and stable fixation compared with untreated eyes with wet AMD.

\section{What this study adds}

- Visual acuity is the only parameter that correlates significantly with the location of fixation. Quantitative parameters on OCT including macular thickness and volume do not influence the location or stability of fixation.

\section{Conflict of interest}

Sobha Sivaprasad has received research grants from Novartis, Allergan, c Pfizer. Victor Chong has received research grants from Pfizer, Novartis, Allergan, and Bayers.

\section{References}

1 Rosenfeld PJ, Brown DM, Heier JS, Boyer DS, Kaiser PK, Chung CY et al, MARINA Study Group. Ranibizumab for neovascular age-related macular degeneration. $N$ Engl J Med 2006; 355(14): 1419-1431.

2 Brown DM, Kaiser PK, Michels M, Soubrane G, Heier JS, Kim RY et al, ANCHOR Study Group. Ranibizumab versus verteporfin for neovascular age-related macular degeneration. N Engl J Med 2006; 355(14): 1432-1444.

3 CATT Research Group, Martin DF, Maguire MG, Ying GS, Grunwald JE, Fine SL, Jaffe GJ. Ranibizumab and bevacizumab for neovascular age-related macular degeneration. N Engl J Med 2011; 364(20): 1897-1908.

4 Gerding H, Loukopoulos V, Riese J, Hefner L, Timmermann M. Results of flexible ranibizumab treatment in age-related macular degeneration and search for parameters with impact on outcome. Graefes Arch Clin Exp Ophthalmol 2011; 249(5): 653-662.

5 Frisen L, Frisen M. Micropsia and visual acuity in macular edema. A study of the neuro-retinal basis of visual acuity. Albrecht Von Graefes Arch Klin Exp Ophthalmol 1979; 2: 69-77.

6 Diabetic Retinopathy Clinical Research Network, Browning DJ, Glassman AR, Aiello LP, Beck RW, Brown DM, Fong DS et al. Relationship between optical coherence tomography-measured central retinal thickness and visual acuity in diabetic macular edema. Ophthalmology 2007; 114: 525-536.

7 Falkenberg HK, Rubin GS, Bex PJ. Acuity, crowding, reading and fixation stability. Vision Res 2007; 47(1): 126-135.

8 Pearce E, Sivaprasad S, Chong NV. Comparing fixation location and stability in patients with neovascular age-related macular degeneration treated with or without Ranibizumab. Eye (Lond) 2011; 25(2): 149-153.
9 González EG, Tarita-Nistor L, Mandelcorn ED, Mandelcorn M, Steinbach MJ. Fixation control before and after treatment for neovascular age-related macular degeneration. Invest Ophthalmol Vis Sci 2011; 52(7): 4208-4213.

10 Fujii GY, De Juan Jr E, Humayun MS, Sunness JS, Chang TS, Rossi JV. Characteristics of visual loss by scanning laser ophthalmoscope microperimetry in eyes with subfoveal choroidal neovascularization secondary to age-related macular degeneration. Am J Ophthalmol 2003; 136(6): 1067-1078.

11 Crossland MD, Dunbar HM, Rubin GS. Fixation stability measurement using the MP1 microperimeter. Retina 2009; 29(5): 651-656.

12 Midena E, Radin PP, Pilotto E, Ghirlando A, Convento E, Varano M. Fixation pattern and macular sensitivity in eyes with subfoveal choroidal neovascularization secondary to age-related macular degeneration. A microperimetry study. Semin Ophthalmol 2004; 19(1-2): 55-61.

13 Tarita-Nistor L, González EG, Markowitz SN, Steinbach MJ. Fixation characteristics of patients with macular degeneration recorded with the mp-1 microperimeter. Retina 2008; 28(1): 125-133.

14 Bolz M, Simader C, Ritter M, Ahlers C, Benesch T, Pruente C et al. Morphological and functional analysis of the loading regimen with intravitreal ranibizumab in neovascular AMD. Br J Ophthalmol 2010; 94(2): 185-189.

15 Parravano M, Oddone F, Tedeschi M, Schiano Lomoriello D, Chiaravalloti A, Ripandelli G et al. Retinal functional changes measured by microperimetry in neovascular age-related macular degeneration patients treated with ranibizumab. Retina 2009; 29(3): 329-334.

16 Holz FG, Korobelnik JF, Lanzetta P, Mitchell P, Schmidt-Erfurth U, Wolf $\mathrm{S}$ et al. The effects of a flexible visual acuity-driven ranibizumab treatment regimen in age-related macular degeneration: outcomes of a drug and disease model. Invest Ophthalmol Vis Sci 2010; 51(1): 405-412.

17 Dadgostar H, Ventura AA, Chung JY, Sharma S, Kaiser PK. Evaluation of injection frequency and visual acuity outcomes for ranibizumab monotherapy in exudative age-related macular degeneration. Ophthalmology 2009; 116(9): 1740-1747.

18 Vujosevic S, Pilotto E, Bottega E, Benetti E, Cavarzeran F, Midena E. Retinal fixation impairment in diabetic macular edema. Retina 2008; 28(10): 1443-1450.

19 Senturk F, Ozdemir H, Karacorlu M, Karacorlu SA, Uysal O. Microperimetric changes after intravitreal triamcinolone acetonide injection for macular edema due to central retinal vein occlusion. Retina 2010; 30(8): 1254-1261.

20 Karacorlu M, Ozdemir H, Senturk F, Karacorlu SA, Uysal O. Macular function after intravitreal triamcinolone acetonide injection for diabetic macular oedema. Acta Ophthalmol 2010; 88(5): 558-563.

21 Ozdemir H, Senturk F, Karacorlu M, Arf Karacorlu S, Uysal O. Macular sensitivity in eyes with central serous chorioretinopathy. Eur J Ophthalmol 2008; 18(5): 799-804.

22 Putnam NM, Hofer HJ, Doble N, Chen L, Carroll J, Williams DR. The locus of fixation and the foveal cone mosaic. J Vis 2005; 5(7): 632-639.

23 Ishiko S, van de Velde F, Yoshida A. Paradoxical improvement of visual acuity in macular disease. Curr Eye Res 2010; 35(7): 651-656. 